A Treatise on Quantitative Inorganic Analysis With Special Reference to the Analysis of Clays, Silicates and Related Minerals. By Dr. J. W. Mellor and H. V. Thompson. Second edition, completely revised and re-set. Pp. xxxi+784. (London: Charles Griffin and Co., Ltd., 1938.) 45s. net.

$\mathrm{I}^{\mathrm{N}}$ view of the excellent reception of the first edition of this book, it is surprising that so many years have been allowed to elapse before the issue of a second one. This was due, no doubt, to the many other calls on the time of the late Dr. Mellor, who finally entrusted to Mr. H. V. Thompson the task of producing a new edition. This task has been efficiently performed, the original text having been thoroughly revised and brought up to date by the incorporation of many of the newer methods and reagents introduced in recent times. Although written primarily from the point of view of analytical practice in the ceramic industry, the work covers practically all the elements and combinations of them which are met with in other analytical fields, so that it can rightly be regarded as a general treatise on quantitative analysis and one of great value to all who carry out complicated analyses.

The subject-matter is arranged according to the plan adopted in the earlier edition, being divided into five sections. These deal respectively with general analytical procedures, typical silicate analysis of glasses, glazes, colours and complex silicates, special methods including procedures for many of the rarer metals and, finally, the analysis of acids and nonmetals. All these are treated in a most detailed and thorough manner, while additional information is often given in footnotes which also contain an excellent and wide selection of references from the literature. Those who have used the first edition will need no recommendation to this revised work, while those who have not, will find it one of the best text-books on its subject.

\section{Rural Community Organization}

By Prof. Dwight Sanderson and Prof. Robert A. Polson. Pp. ix +448. (New York : John Wiley and Sons, Inc.; London: Chapman and Hall, Ltd., 1939.) 18s. net.

THIS book is a contribution to the solution of 1 the old question whether man can control his social relations by taking thought as he does control the world of things. Organization of social relations must be based on an understanding of the facts. The authors state that to aim at organizing a rural community in a mechanical way such as is implied in 'social engineering' is vain, and they assert that "rural social organization is the art of planning social relationships in the rural environment by use of the methods of science". They do not, however, give more than passing reference to possible scientific methods of approach to the problems they discuss : the science they have in mind is the rather vague one of sociology, and it appears as if they had no conception of the possibilities of modern statistical reasoning. The book is an able exposition of applied psychology, illustrated with many well-documented examples of what has been done in the field of rural community organization in the United States. However empirically this has been performed, it is a beginning which offers useful lessons and can be developed. The chapter analysing community conflict and clashes of interest is novel and is particularly trenchant. The book presupposes that the student will have had a course in general sociology or rural sociology, but this is said not to be essential for mature students who have had personal experience in rural life.

\section{Food Control, its Public-Health Aspects}

A Manual for Regulatory Officers, Food Technologists and Students of the Food Industry. By Dr. James Houston Shrader. Pp. ix +513 . (New York: John Wiley and Sons, Inc.; London: Chapman and Hall, Ltd., 9.9.) 24s. net.

A LTHOUGH Dr. Shrader's volume is written A primarily for the American reader and is concerned mainly with United States public health administration, it will be welcomed by many in Great Britain as a valuable and concise manual. The author surveys a very wide field and, on the whole, does so with commendable balance and sense of proportion. In most respects his treatment is up to date. This is particularly true of his descriptions of the technical side of food preparation and manufacture. By contrast one comes now and again to sections where his knowledge is curiously behind what we should expect. Thus, for example, although compiled in the early part of last year, the section on the vitamins is far from adequate. There is merely passing reference to nicotinic acid, $B_{6}$ is not mentioned, and attention is not directed to the important differentiation between $D_{2}$ and $D_{3}$. However, any small disappointment these minor faults may provoke is soon dispelled by appreciation of the merits of the book as a whole. They are many and they far outweigh the defects, not the least of which is the use of dreadful terms such as 'organoleptic acceptance'. Shall we live to see a hoarding bearing the slogan 'Guinness is organoleptically acceptable' ?

$$
\text { J. C. D. }
$$

Human Histology,

A Guide for Medical Students. By Dr. E. R. A. Cooper. Pp. xiv +424. (London: H. K. Lewis and Co., Ltd., 1939.) 16s. net.

DR. E. R. A. COOPER, lecturer in histology at the University of Manchester, whose work is introduced by Prof. F. Wood Jones, the professor of anatomy, is to be warmly congratulated on the production of a text-book which will be of the utmost value to the medical student and graduate both in the laboratory and in the study. The volume, which is clearly and concisely written, consists of twentyone chapters dealing with the microscopic anatomy of the various systems and organs. A remarkable and praiseworthy feature is the insertion at the end of each chapter of a practical examination to be carried out by the reader.

The text is liberally interspersed with microphotographs, and an excellent index is supplied. 